\title{
Modelling the tides and their impacts on the vertical stratification over the Sofala Bank, Mozambique
}

\author{
Chevane $\mathrm{Cm}^{1,4,{ }^{*}}$, Penven Pierrick ${ }^{2}$, Nehama Fpj $^{3,4}$, Reason Cjc ${ }^{4}$ \\ ${ }^{1}$ Instituto Nacional de Hidrografia e Navegação, Maputo, Mozambique \\ ${ }^{2}$ LMI ICEMASA, Laboratoire de Physique des Océans, UMR 6523 (CNRS, Ifremer, IRD, UBO), \\ Plouzané, France \\ ${ }^{3}$ Escola Superior de Ciências Marinhas e Costeiras, UEM, Quelimane, Mozambique \\ ${ }^{4}$ Department of Oceanography, University of Cape Town, Cape Town, South Africa \\ *Corresponding author : CM Chevane, email address : clousamaueua@gmail.com
}

\begin{abstract}
:
The Sofala Bank, a wide shelf located along the central coast of Mozambique, hosts tides with high amplitudes. The Regional Ocean Modelling System (ROMS) was used to analyse the tidal currents on the bank and to investigate their effects on the stratification and generation of tidal fronts. During spring tides, barotropic tidal currents with maximum values ranging from $40 \mathrm{~cm} \mathrm{~s}-1$ to $70 \mathrm{~cm} \mathrm{~s}-1$ are found on the central bank. The major axis of the tidal ellipses for M2 and S2 follow a cross-shelf direction with mainly anticlockwise rotation. Similar to observations, three distinct regimes occur: (i) a warm wellmixed region on the inner shelf where the depths are $<30 \mathrm{~m}$; (ii) a wellmixed colder region above the shelf edge; and (iii) a stratified region offshore. The model shows that the tides lead to cooling where two criteria are satisfied: the Simpson and Hunter parameter $\log 10(\mathrm{~h} / \mathrm{U} 3)<3.2$ and the depth $\mathrm{h}>30 \mathrm{~m}$. The shelf edge of the bank is important for internal tide generation. Two frontal structures result, one offshore between cooler mixed waters and warmer stratified waters and the other in shallow inshore waters, between cooler mixed waters and solar heated mixed waters.
\end{abstract}

Keywords : barotropic tidal currents, ROMS, sea surface temperature, shallow seas, tidal front 


\section{Introduction}

The Sofala Bank (hereafter referred to as 'the bank') is a large and shallow shelf extending from the coast of Mozambique in the central Mozambique Channel from $17^{\circ} \mathrm{S}$ to $21^{\circ} \mathrm{S}$ (Figure 1). It has an average depth of about $30 \mathrm{~m}$ and is approximately $150 \mathrm{~km}$ wide and 500 $\mathrm{km}$ long. The bank hosts an important shrimp fishery dominated by two species, Penaeus indicus and Metapenaeus monoceros (Sousa et al. 2006). According to Gammelsrod (1992), these species comprised $48 \%$ of shrimp catches on the bank in the early 1990s. From 2000 to 2002 , the annual average industrial shrimp catch was $8600 \mathrm{t}$, with $P$. indicus and $M$. monoceros accounting for $4600 \mathrm{t}$ and $2500 \mathrm{t}$, respectively (Sousa et al. 2006).

Several rivers discharge onto the bank, with the Zambezi River being the main source of fresh water. As a consequence, the bottom topography on the bank consists predominantly of fine gravel and sand sediments from Zambezi run-off (Schulz et al. 2011).

The ocean circulation on the bank is influenced by the passing of large Mozambique Channel rings drifting mainly southward in the central channel (Halo et al. 2014; Malauene 2014). The ocean circulation on the bank is also wind-forced, presenting seasonal variations, which are strongest from October to February because of the predominance of southeasterly trade winds during this period (Saetre 1985).

The Sofala Bank region hosts the largest tides in the western Indian Ocean (Figure 2), reaching an amplitude of $6.6 \mathrm{~m}$ during spring tides (Hoguane 2007; da Silva et al. 2009). Tides on the bank follow a semi-diurnal regime, with a cycle of two high and two low tidal amplitudes during the day. The $\mathrm{M}_{2}$ tidal constituent is predominant, reaching an amplitude of $>2 \mathrm{~m}$ inshore (Figure 2). The tidal cycle appears to affect nutrient transport mechanisms. According to Leal et al. (2009), the phytoplankton biomass is transported offshore during ebbing tides. It is also during the low tide that the highest concentrations of nutrients, such as nitrates, phosphates and silicates, are found at bottom depths of the bank (Leal et al. 2009).

The bank has four distinct water masses, namely: low salinity shelf water; warmer oceanic surface waters; deep oceanic waters; and high salinity shelf water (Nehama et al. 2015). The surface waters are warm during the austral summer (December-March) due to surface heating, resulting in a high level of vertical stratification (da Silva et al. 2009). The presence of stratification and important mixing induced by large tidal currents could lead to the generation of tidal fronts. These fronts are generated in a transition zone between tidally 
mixed waters and stratified waters in shallow seas (Hill et al. 1993). Tidal fronts could be responsible for an enhanced regeneration of nutrients of importance for biological productivity (Pingree et al. 1978) and for the distribution of fish larvae (Lough and Manning 2001).

Several studies related to the shrimp fishery have been conducted on the bank (Gammelsrod 1992; Sousa et al. 2006; Fennessy and Isaksen 2007), but tidal characteristics, and particularly the effects of tides on the vertical stratification and the mean ocean circulation on the bank, remain poorly understood. In this context, a three-dimensional numerical model has been designed to resolve the tides on the bank and their effects on the vertical oceanic structure. A comparison of model solutions with and without tides illustrates the effects of tides on the mean vertical stratification on bank. We present the model, describe the tides and compare the model output with observations from a coastal tide gauge in the harbour of Beira. An analysis of the effects of tides on the vertical stratification on the bank concludes the study.

\section{Methods}

\section{The ocean model}

We used the Regional Ocean Modelling System (ROMS), a realistic three-dimensional oceanographic model that solves the primitive equations with a stretched terrain-following vertical coordinate (Shchepetkin and McWilliams 2005; Debreu et al. 2012). As a freesurface and split-explicit oceanic model, it uses shorter time-steps to advance the surface elevation and the barotropic momentum equations and longer time-steps for the baroclinic momentum and tracer equations. The time-stepping algorithm is based on a predictorcorrector formulation. The model baroclinic time-step is 10 minutes. The unresolved physical mixing processes are parameterised with a non-local K-profile parameterisation (Large et al. 1994) with both a surface- and a bottom-boundary-layer parameterisation. The model configuration was generated with the MATLAB ROMSTOOLS package (Penven et al. 2008). The model domain is an oblique grid, encompassing the region $30^{\circ}-47^{\circ} \mathrm{E}$ and $10^{\circ}-30^{\circ} \mathrm{S}$ with a resolution of $6.3 \mathrm{~km}$, and such that the $y$-direction is aligned with the Mozambique coastline (Figure 1). The model bathymetry was derived from the Global Earth Bathymetric Chart of the Oceans (GEBCO) 1'-resolution dataset and was smoothed to reduce the 'slope parameter' to 0.25 (Penven et al. 2008). The vertical grid was divided into 50 terrainfollowing layers with the following stretching parameters: $\theta_{\mathrm{s}}=5.5, \theta_{\mathrm{b}}=0$ and $h_{\mathrm{c}}=10 \mathrm{~m}$ (Haidvogel and Beckmann 1999). The sea-surface forcing such as momentum, heat and freshwater fluxes were obtained from Comprehensive Ocean-Atmosphere Data Sets 
(COADS; da Silva et al. 1994). We used a quadratic bottom-friction parameterisation based on a logarithmic profile with a roughness height of $0.25 \mathrm{~cm}$.

The barotropic tides are introduced at the model lateral open boundaries using a Flather radiation condition (Flather 1976) to force velocities and sea surface elevations from the TPXO global tidal solution (Egbert and Erofeeva 2002). Barotropic tidal data were obtained from TPXO 7.0 for the 10 principal constituents $\left(M_{2}, S_{2}, N_{2}, K_{2}, K_{1}, O_{1}, P_{1}, Q_{1}, M_{f}, M_{m}\right)$. The dominant tidal constituents on the bank are the principal lunar semi-diurnal, $M_{2}$, and the principal solar semi-diurnal, $S_{2}$ (da Silva et al. 2009) (Figure 2).

Three different simulations were conducted. First, a short (100 days) simulation with a 30minute sampling interval for the barotropic velocity components and sea surface elevation and using World Ocean Atlas 2005 climatology (Locarnini et al. 2010) at the open boundaries was used for the description of the tides on the bank. Second, to test the effect of tides on the vertical temperature structure on the shelf, two long simulations (10 years) were conducted with the outputs of a model solution of the western Indian Ocean saved at 2day intervals, as it resolves the mesoscale dynamics (South-West Indian Ocean Model [SWIM]; Halo et al. 2014) used as lateral boundary conditions. This is based on the ROMS2ROMS approach (Mason et al. 2010). One simulation is run with tidal forcing and the other without. Sufficiently long statistics from the experiments were derived using the model outputs saved every 2 days for all the variables from Year 3 to Year 10.

A harmonic analysis of oceanic tides was performed on the model outputs using T_tide, a package of MATLAB routines used to perform classical harmonic analysis and to predict tides using known constituents (Pawlowicz et al. 2002).

\section{Tidal measurements}

The model outputs were compared with hourly sea surface height measurements collected using an OTT R20 float-type tide gauge (serial number: 20102). The tide gauge was moored at a depth of $3.56 \mathrm{~m}$ and located at $19.84^{\circ} \mathrm{S}, 34.83^{\circ} \mathrm{E}$, in the mouth of the Pungwe River in Beira (Figure 1). Data were collected from 16:00 (local time), 9 January 1998, to 00:00, 25 January 1998.

\section{Pathfinder satellite data and CARS 2009 climatology}

The model sea surface temperature was compared with the Pathfinder 5.0 monthly climatology of sea surface temperature. The Pathfinder data were derived from Advanced 
Very High Resolution Radiometer (AVHRR) observations from 1981 to 2009, gridded at a resolution of $4 \mathrm{~km}$ (Casey et al. 2010).

The mean vertical model stratification was compared with the annual mean temperature from CSIRO Atlas of Regional Seas (CARS) 2009 climatology data (Dunn and Ridgway 2002). CARS 2009 is a climatology of global ocean properties gridded at $1 / 2^{\circ}$ resolution.

\section{Criterion for tidal front identification}

As tidal fronts delimit the boundary between regions that are vertically stratified due to surface heating, and tidally well-mixed waters, Simpson and Hunter (1974) derived a criterion from energy considerations for the location of the fronts. This criterion is based on the balance between the potential energy induced by surface heating and the energy loss by tidal motions at the bottom. It results in a relationship ' $h / U^{\beta}=$ const.' (where $h$ is the water depth, $U$ is the current velocity near the bottom and the constant depends on the surface heating $Q$ and on wind regime), predicting the position of the front from tidal velocities. This criterion has been applied with success in different shelf seas worldwide (Garrett et al. 1978; Mariette and Le Cann 1985; Cambon 2008). We used the maximum barotropic currents on the shelf for the tidal velocity $U$.

\section{Results}

\section{Comparison of ROMS and TPXO with tide-gauge observations}

The time-series of sea surface elevation at the tide-gauge location in Beira during January 1998 for the observations, the TPXO model and the ROMS simulation are presented in Figure 3. The time-series encompasses a complete spring- to neap-tide cycle. A slightly mixed semi-diurnal cycle is evident. The TPXO grid, at $0.25^{\circ}$ resolution, did not resolve the mouth of the Pungwe River and extrapolating the data for this location gave incorrect results. However, using the closest point offshore, at $20^{\circ} \mathrm{S}, 35.05^{\circ} \mathrm{E}$, produced a more reasonable tidal cycle. This problem did not occur with ROMS, which represented the tidal cycle for the region reasonably well, but both TPXO and ROMS underestimated the amplitude of the tide. This discrepancy might be related to the position of the tide gauge in the Pungwe River, which was not fully resolved by ROMS or TPXO. Forced by TPXO at its lateral boundaries, ROMS was able to propagate barotropic tides on the Sofala Bank. 


\section{General characteristics of the modelled tides on the Sofala Bank}

Figures 4 and 5 represent the sea surface height and barotropic currents every two hours for a typical spring tidal cycle on 28 March of Model Year 1. High tidal amplitude (in absolute terms) is found inshore, at the widest part of the bank. From there, it decreases in a southeastward direction. Figure $4 a$ shows the elevation at high tide with amplitude decreasing from $2.9 \mathrm{~m}$ at the coast at Beira to $1.9 \mathrm{~m}$ at the shelf edge. The maximum is located in the Pungwe River and the amplitude reduces along almost-straight lines parallel to the bathymetry. Two hours later (Figure 4b), the sea surface height is reduced to almost half of the previous value. Four hours after high tide (Figure 4c), the amplitude is almost uniform across the bank. The negative signal offshore indicates a tidal flow back towards the coast. The low tide (Figure 4d) presents an almost-symmetrically opposite pattern compared to high tide, with an amplitude of $-2.7 \mathrm{~m}$ inshore. Over the following four hours (Figures $4 \mathrm{e}$ and $4 f)$, sea level returns towards the high-tide state.

The barotropic currents for the spring tides are shown in Figure 5 for the same time-period and intervals. The currents on the shelf generally follow a counterclockwise rotation from a southward direction (Figure 5a) to south-eastward (Figure 5b), eastward (Figure 5c) and then northward (Figure 5d). Figures $5 e$ and $5 f$ show few direction variations, with the current flowing in a north-eastward direction. The southward direction of the current is found during high tide (Figure $5 \mathrm{a}$ ) and northward during low tide (Figure $5 \mathrm{~d}$ ). The southward direction in panel $5 \mathrm{a}$ is consistent with the findings of Leal et al. (2009). The maximum speeds are in the range $40-70 \mathrm{~cm} \mathrm{~s}^{-1}$ and are found on the central part of the bank during ebbing tides (Figures $5 b, 5 c$ ), as well as flooding tides (Figures $5 e, 5 f$ ). However, the values for flooding are slightly higher than those for ebbing. This asymmetry is in agreement with the theory predicting a longer ebb balanced by shorter more intense flow in shallow water (Huthnance 1973). The maximum values of the barotropic tidal currents are found in the region between $19.5-21^{\circ} \mathrm{S}$ and $34.8-36^{\circ} \mathrm{E}$ on the south side of the bank (Figures $5 \mathrm{~b}, 5 \mathrm{c}, 5 \mathrm{e}, 5 \mathrm{f}$ ). The maximum current values $\left(>50 \mathrm{~cm} \mathrm{~s}^{-1}\right.$ ) are in agreement with the values found by da Silva et al. (2009). Greater velocities during the intermediate tidal periods are also consistent with the findings of Hoguane (2007).

The semi-diurnal $M_{2}$ and $S_{2}$ components, which are dominant on the bank, were extracted from the modelled barotropic velocities and free surface elevation using T_tides (Pawlowicz et al. 2002). $M_{2}$ and $S_{2}$ tidal amplitudes and phases are presented for ROMS and TPXO in Figure 6. As was shown in Figure 4, tidal amplitudes (which are already large in deep water, with values of $100 \mathrm{~cm}$ for both ROMS and TPXO) increase on the bank towards the mouth of the Pungwe River. Although the maximum values in ROMS $(205 \mathrm{~cm})$ and TPXO $(209 \mathrm{~cm})$ 
are very similar, the position of the maximum in TPXO lies slightly to the north of that in ROMS (Figure 6). A similar pattern is presented by $S_{2}$ tidal amplitudes but with approximately half the amplitude presented by $M_{2}$. As indicated in Figures 2 and 5 , phases for $M_{2}$ and $S_{2}$ in the region do not present important variations around a mean value of $45^{\circ}$ for $M_{2}$ and $90^{\circ}$ for $S_{2}$ (Figures $6 \mathrm{c}, 6 \mathrm{~d}$ ). Nevertheless, TPXO presents a phase shift of about $15^{\circ}$ in the north of the bank. This latter pattern is unexpected and would need to be confirmed by in situ observations. The tidal current ellipses for $M_{2}$ and $S_{2}$ are presented in Figures $6 \mathrm{e}, \mathrm{f}$. In agreement with Figure 5, the rotations of the ellipses are mostly counterclockwise on the bank. The major axis of the currents is oriented zonally, following a cross-shelf direction. The patterns for $\mathrm{M}_{2}$ and $\mathrm{S}_{2}$ are similar, with an amplitude increasing from the north to the centre of the bank. The strongest currents are in the central part of the bank and decrease in the south. The tidal current amplitude also decreases markedly at the shelf break. The $M_{2}$ tide is dominant, with a current amplitude larger than $S_{2}$. A clockwise rotation of the currents can be observed at the coast for both $\mathrm{M}_{2}$ and $\mathrm{S}_{2}$. Close to the shore, on the inner shelf, ellipse eccentricities are close to 1 for both $M_{2}$ and $S_{2}$ (Figures $6 e, f$ ).

Figure 7 presents the mean and $95^{\text {th }}$ percentile of the kinematic bottom stress induced by the tides on the bank. Large values are found on the central part of the bank, reaching $0.5 \mathrm{~N}$ $\mathrm{m}^{-2}$ for the $95^{\text {th }}$ percentile between $20^{\circ} \mathrm{S}$ and $21^{\circ} \mathrm{S}$. Bottom stress is much weaker inshore, on the shelf edge and towards the north. This is consistent with the distribution of maximum velocities seen in Figure 5. These large contrasts in bottom stress could help explain the sediment deposit patterns observed by Schultz et al. (2011), showing less deposition toward the south of the bank.

\section{Modelling tidal effects on vertical stratification on the bank}

Figure 8 presents a vertical section of annual mean temperature across the bank from the 10-year experiment and CARS 2009 (Dunn and Ridgway 2002). Offshore, both ROMS and CARS present a mean slope upward toward the shelf edge, consistent with a mean poleward flow along the shelf edge. The thermocline appears slightly shallower for ROMS, but values are in general comparable. At the surface and subsurface above the shelf break, both ROMS and CARS show cooler temperature than the surroundings and the outcropping of the $26{ }^{\circ} \mathrm{C}$ isotherm. It is surprising that a large-scale product such as CARS is able to capture such a localised process. On the shelf, ROMS appears warmer and more mixed than CARS.

Figure 9a represents the annual mean sea surface temperature (SST) for the long (10-year) simulation with tides. The SST shows warmer waters $\left(>26.8^{\circ} \mathrm{C}\right)$ inshore of the $40 \mathrm{~m}$ isobath, 
cooler temperatures $\left(<25.4{ }^{\circ} \mathrm{C}\right)$ between the $50 \mathrm{~m}$ and $100 \mathrm{~m}$ isobaths and temperatures in the range $26-27^{\circ} \mathrm{C}$ (decreasing southward) offshore. Figure 9b presents a vertical section of temperature along a line across the bank. It shows three distinct regimes: (I) a well-mixed warm region, between $34.8^{\circ} \mathrm{E}$ and $35.4^{\circ} \mathrm{E}$, on the inner shelf where depths are $<30 \mathrm{~m}$; (II) a well-mixed cooler region, between $35.4^{\circ} \mathrm{E}$ and $35.8^{\circ} \mathrm{E}$; and (III) a stratified region offshore. Along the line that divides stratified from homogeneous water columns, there is a horizontal front in a well-mixed cooler region (between $35.5^{\circ} \mathrm{E}$ and $35.6^{\circ} \mathrm{E}$ ) and in the depth range 30 $\mathrm{m}<h<60 \mathrm{~m}$. Figures $9 \mathrm{a}$ and $9 \mathrm{~b}$ are consistent in terms of thermal structure. The warm boundary inshore of the $40 \mathrm{~m}$ isobath in Figure 9a corresponds to the warm mixed region in Figure $9 \mathrm{~b}$. The cooler region between the $40 \mathrm{~m}$ and $100 \mathrm{~m}$ isobaths, south of $19^{\circ} \mathrm{S}$ in Figure $9 \mathrm{a}$, is in agreement with the well-mixed cooler region of Figure 9b. The warmer region offshore in Figure 9a corresponds to the stratified region in Figure 9b. The SST range in the transition band between well-mixed and stratified regions is between $25.5{ }^{\circ} \mathrm{C}$ and $26{ }^{\circ} \mathrm{C}$ (Figures 9a, b).

The annual mean SST for the Pathfinder monthly climatology is presented in Figure 10. Three different regions are again evident: (I) a warmer region near the coast, ranging from $26.6{ }^{\circ} \mathrm{C}$ (close to the coast) to $26.2^{\circ} \mathrm{C}$ (at the shelf edge); (II) a cooler region at the shelf break, with temperature values between $25.8^{\circ} \mathrm{C}$ and $26.2^{\circ} \mathrm{C}$; and (III) a slightly less cool region offshore, presenting a north-south temperature range from $26.5^{\circ} \mathrm{C}$ to $27.3^{\circ} \mathrm{C}$.

To test the effects of tides, a similar model experiment was run without tides. The modelled annual mean SST is presented in Figure 11a. Although there are still cooler waters on the shelf edge, it is warmer $\left(26{ }^{\circ} \mathrm{C}\right)$ than for the simulation with tides $\left(25.4^{\circ} \mathrm{C}\right)$. Furthermore, the horizontal gradients are weaker in the experiment without tides. Inshore, the SST is cooler $\left(26.6^{\circ} \mathrm{C}\right)$ than for the simulation with tides $\left(26.8^{\circ} \mathrm{C}\right)$. There is still a doming of the isotherms at the shelf edge, but the $26^{\circ} \mathrm{C}$ isotherm no longer outcrops (Figure $11 \mathrm{~b}$ ).

These patterns are apparent in the difference in SST between the simulation with tides and that without tides (Figure 12). A positive anomaly of $0.2-0.3{ }^{\circ} \mathrm{C}$ occurs inshore of the $40 \mathrm{~m}$ isobath. A larger, negative anomaly, reaching $1^{\circ} \mathrm{C}$, extends between the $40 \mathrm{~m}$ isobath and the shelf edge. Contours of the parameter $\log _{10}\left(h / U^{3}\right)$ are also presented in Figure 12 , accounting for the mixing induced by the tides. Minimum values (reaching 1.8) are evident on the southern part of the bank. The offshore edge of the negative anomaly follows the 3.2 contour. Inshore of this, the water is well-mixed, but when the depth is $<30 \mathrm{~m}$, solar heating is able to penetrate the entire water column (see Figure). Taking into account these two 
processes (tidal mixing and full solar heating in shallow water), the red contour in Figure 12 satisfies the criteria: $\log _{10}\left(h / U^{3}\right)<3.2$ and $h>30 \mathrm{~m}$. This contour is able to delimit the core of the colder anomaly induced by the tides (Figure 10) and illustrates how tidal mixing could participate to create a region of lower SST on the outer edge of the bank. Hence, there are indications that the bank hosts two tidal fronts that are visible in long-term climatological observations (Figure 10). One front appears to be offshore between cooler mixed waters and warmer stratified waters and the other is inshore between cooled mixed waters and solarheated mixed waters in shallow water (Figure 9, 10). In addition, internal tides can also have an important cooling effect at the shelf edge.

\section{Discussion}

Our model simulation suggests that cooler temperatures could be present on the southeastern part of the Sofala Bank. The presence of a tongue of cooler water at the same place in the observed SST images corroborates this finding. This particular process does not seem to have been described previously for the bank. Although tidal fronts have been studied in shelf waters in Europe (Simpson and Hunter 1974; Mariette and Le Cann 1985; Bowers and Simpson 1987; Cambon 2008) and North America (Loder and Greenberg 1986; Franks and Chen 1996) shelves, very few studies have been conducted for the south-western Indian Ocean (Hatayama et al, 1996; Lencart et al, 2010; Machaieie, 2010; Tovela 2012). Figure 2 shows that, the, $\mathrm{M}_{2}$ tides are important in the western Indian Ocean particularly in the Mozambique Channel these tides are the most dominant. . It is possible that, in low latitudes, large air-sea heat fluxes might inhibit the surface signature of tidal fronts. However, another example of a tropical tidal front is in a region of the Great Barrier Reef at $19^{\circ} \mathrm{S}$ (Kingsford et al. 1991). In addition, the Indonesian Seas represent a low-latitude region where tidal mixing influences SST (Ffield and Gordon 1996).

Although mixing induced by tidal friction could be an important factor on the shallower part of the bank, this is less clear for the shelf edge. Da Silva et al. (2009) showed that the region offshore of the bank is a hotspot for the generation of internal tides and internal waves. Although the resolution in our study is coarse $(6.3 \mathrm{~km})$ compared to the wavelengths observed by da Silva et al. (2009) $(0.5-7 \mathrm{~km})$, the model nevertheless generates internal tides at the shelf break. This is illustrated in Figure 13 by a series of vertical temperature sections at 2-hour intervals on the $9^{\text {th }}$ of March of Model Year 10, in which isotherms show large excursions during spring tides on the shelf edge. These excursions reach more than 50 $\mathrm{m}$ at around $150 \mathrm{~m}$ depth (Figure 13). This process is probably important in explaining the 
presence of cooler water on the shelf edge and should be investigated further, by means of dedicated studies using higher resolution models for internal tides in this region.

In addition, although our 'tide / no tide' model comparison provided confidence that a large amount of the cooler water present on the shelf edge of the bank could be explained by mixing induced by tidal friction and internal tides, interactions between Mozambique Channel Rings and bottom topography might also bring colder water onto the shelf (Malauene 2014). Although less pronounced, a tongue of cooler water is present at the shelf break even in the long simulation without tides. This process should be tested in further studies. Tidal fronts are known to be important for plankton production (Franks and Chen 1996) and fish larval transport and retention (Lough and Manning 2001). Thus, there is a need for dedicated in situ observations and Lagrangian numerical experiments to investigate additional aspects of the newly described tidal front on the Sofala Bank'.

\section{Conclusion}

The Sofala Bank has been studied in the past in terms of marine biology (Gammelsrod 1992; Sousa et al. 2006; Leal et al. 2009). However, tidal characteristics and their influence on mean water properties remain poorly investigated. Here, we used a numerical model to investigate the general characteristics of the tides on the bank and their effects on vertical stratification.

The model simulation is able to represent the tidal cycles on the bank. High tidal amplitude is found inshore, on the widest part of the bank. It decreases towards the east, north and south. During spring tides, barotropic tidal currents of maximum values ranging from $40 \mathrm{~cm}$ $\mathrm{s}^{-1}$ to $70 \mathrm{~cm} \mathrm{~s}^{-1}$ are found on the central part of the bank during ebbing and flooding (with higher values for flooding). The major axis of the tidal ellipses for $M_{2}$ and $S_{2}$ follow a crossshelf direction, while the rotations are predominantly counterclockwise.

Modelled temperature at the end of summer shows three distinct regimes: (I) a warm wellmixed region on the inner shelf in depths $<30 \mathrm{~m}$; (II) a well-mixed cooler region over the shelf edge; and (III) a stratified region offshore. These three regions are also evident in Pathfinder climatology data. This pattern depends on the presence of tides. Therefore, a comparison of two simulations, one with tides and one without tides, was conducted, and shows a negative anomaly, reaching $1{ }^{\circ} \mathrm{C}$, extending between the $40 \mathrm{~m}$ isobath and the shelf edge. This anomaly coincides with the conjunction of two criteria: the Simpson and Hunter (1974) parameter $\log _{10}\left(h / \cup^{3}\right)<3.2$ and the bottom topography $h>30 \mathrm{~m}$. This region 
also coincides with the generation of large internal tides. This illustrates how tidal and internal mixing are able to create a region of cooler SST on the outer edge of the bank. As a result, there are two frontal structures, one offshore between cooler mixed waters and warmer stratified waters and the other in shallow inshore waters between cooled mixed waters and solar-heated mixed waters. However, in situ observations are necessary to confirm the existence of these fronts that are evident in the model experiments and the satellite data.

Acknowledgements - The GEBCO Digital Atlas is published on CD-ROM on behalf of the Intergovernmental Oceanographic Commission and the International Hydrographic Organization as part of the General Bathymetric Chart of the Oceans, British Oceanographic Data Centre, Liverpool, UK. Pathfinder 4-km data were provided by the Group for High Resolution Sea Surface Temperatures (GHRSST) and the US National Oceanographic Data Center. This project was supported in part by a grant from the National Oceanic and Atmospheric Administration (NOAA) Climate Data Record (CDR) Program for satellites. This work is a contribution to the JEAI MOCA, funded by the Institut de Recherche pour le Développement (IRD). We acknowledge the financial support given to this research by the Western Indian Ocean Marine Science Association (WIOMSA) MARG II programme.

\section{References}

Bowers D, Simpson J. 1987. Mean position of tidal fronts in European-shelf seas. Continental Shelf Research 7: 35-44.

Cambon G. 2008. Etude numérique de la merd'Iroise: dynamique, variabilité du front d'Ouessant et évaluation des échanges cross-frontaux. PhD thesis, Université de Bretagne Occidentale, Brest, France.

Casey KS, Brandon TB, Cornillon P, Evans R. 2010. The past, present and future of the AVHRR Pathfinder SST Program. In: Barale V, Gower JFR, Alberotanza L (eds), Oceanography from space: revisited. Netherlands: Springer.

da Silva AM, Young CC, Levitus S. 1994. Atlas of surface marine data, Volume 1: algorithms and procedures. USA: US Department of Commerce, National Oceanic and Atmospheric Administration.

da Silva JC, New AL, Magalhaes JM. 2009. Internal solitary waves in the Mozambique Channel: observations and interpretation. Journal of Geophysical Research 114: 1-12. 
Debreu L, Marchesiello P, Penven P, Cambon G. 2011. Two-way nesting in split-explicit ocean models: algorithms, implementation and validation. Ocean Modelling 49-50: 1-21.

Dunn, JR, Ridgway, KR. 2002. Mapping ocean properties in regions of complex topography. DeepSea Research 49: 591-604.

Egbert GD, Erofeeva SY. 2002. Efficient inverse modeling of barotropic ocean tides. Journal of Atmospheric and Oceanic Technology 19: 183-204.

Fennessy ST, Isaksen B. 2007. Can bycatch reduction devices be implemented successfully on prawn trawlers in the western Indian Ocean? African Journal of Marine Sciences 29: 453463.

Ffield A, Gordon AL. 1996. Tidal mixing signatures in the Indonesian Seas. Journal of Physical Oceanography 26: 1924-1937.

Flather RA. 1976. A tidal model of the northwest European continental shelf. Mémoires de la Société royale des sciences de Liège 10: 141-164.

Franks PJS, Chen C. 1996. Plankton production in tidal fronts: a model of Georges Bank in summer. Journal of Marine Research 54: 631-651.

Gammelsrod T. 1992. Variation in shrimp abundance on the Sofala Bank, Mozambique, and its relationship to the Zambezi River runoff. Estuarine, Coastal and Shelf Science 35: 91-103.

Garrett CJR, Keeley JR, Greenberg DA. 1978. Tidal mixing versus thermal stratification in the Bay of Fundy and Gulf of Maine. Atmosphere-Ocean 16: 403-423.

Haidvogel D, Beckmann A. 1999. Numerical ocean circulation modeling. London, UK: Imperial College Press.

Halo I, Backeberg B, Penven P, Ansorge I, Reason C, Ullgren JE. 2014. Eddy properties in the Mozambique Channel: a comparison between observations and two numerical ocean circulation models. Deep-Sea Research Part I/ 100: 38-53.

Hatayama T, Awaji T, Akitomo K. 1996. Tidal currents in the Indonesian Sea and their effect on transport and mixing. Journal of Geophysical Research 1001 Issue C5: 12353-12373.

Hill AE, James ID, Linden PF, Matthews JP, Prandle D, Simpson JH et al. 1993. Dynamics of tidal mixing in the North Sea. Philosophical Transactions of the Royal Society of London A 343: 431-446. 
Hoguane AM. 2007. Perfil diagnostico da zona costeira de Mocambique. Integrated Coastal Zone Management 7: 69-82.

Huthnance JM. 1973. Tidal currents asymmetries over the Norfolk Sandbanks. Estuarine and Coastal Marine Science 1: 89-99.

Kingsford MJ, Wolanski E, Choat JH. 1991. Influence of tidally induced fronts and Langmuir circulations on distribution and movements of presettlement fishes around a coral reef. Marine Biology 109: 167-180.

Large WG, McWilliams J, and Doney SC. 1994: Oceanic vertical mixing: a review and a model with a nonlocal boundary layer parameterization. Reviews of Geophysics 32: 363-403.

Leal M, Sá C, Nordez S, Brotas V, Paula J. 2009. Distribution and vertical dynamics of planktonic communities of Sofala Bank, Mozambique. Estuarine, Coastal and Shelf Science 84: 605616.

Lencart e Silva JD, Simpson JH, Hoguane AM, Harcourt-Baldwin J-L. 2010. Buoncy-stirring interaction in a subtropical embayment: a synthesis of measurements and model simulation in Maputo Bay, Mozambique. African Journal of Marine Sciences 32(1): 85-107.

Locarnini RA, Mishonov AM, Antonov JI, Boyer TP, Garcia HE, Baranova OK, Zweng MM, and Johnson DR. 2010: World Ocean Atlas 2009, Volume 1: Temperature. Tech. rep., NOAA Atlas NESDIS 68, U.S. Government Printing Office, Washington, D.C.

Loder JW, Greenberg DA. 1986. Predicted positions of tidal fronts in the Gulf of Maine region. Continental Shelf Research 6: 397-414.

Lough PR, Manning JP. 2001. Tidal-front entrainment and retention of fish larvae on the southern flank of Georges Bank. Deep-Sea Research I/ 48: 631-644.

Machaieie HE. 2012. Water masses, Circulation, stratification and fronts in Sofala Bank. Master thesis. Eduardo Mondlane University.

Malauene BS. 2014. Environmental influences on banana shrimps of the Sofala Bank, Mozambique Channel. PhD thesis, University of Cape Town, South Africa.

Mariette V, Le Cann B. 1985. Simulation of the formation of Ushant thermal front. Continental Shelf Research 4: 637-660. 
Mason E, Molemaker J, Shchepetkin AF, Colas F, McWilliams JC, Sangrà P. 2010. Procedures for offline grid nesting in regional ocean models. Ocean Modelling 35: 1-15.

Nehama FPJ, Lemos MA, Machaieie HA. 2015. Water mass characteristics in a shallow bank highly influenced by river discharges: the Sofala Bank in Mozambique. Journal of Integrated Coastal Zone Management 15: 523-532.

Pawlowicz R, Beardsley B, Lentz S. 2002. Classical tidal harmonic analysis including error estimates in MATLAB using T_TIDE. Computers and Geosciences 28: 929-937.

Penven P, Marchesiello P, Debreu L, Lefevre J. 2008. Software tools for pre- and post-processing of oceanic regional simulations. Environmental Modelling and Software 23: 660-662.

Pingree RD, Holligan PM, Mardell GT. 1978. The effects of vertical stability on phytoplankton distribution in the summer on the northwest European Shelf. Deep-Sea Research 25: $1011-$ 1028.

Saetre R. 1985. Surface currents in the Mozambique Channel. Deep-Sea Research Part I 32: 14571467.

Schulz H, Luckge A, Emeis KC, Mackensen A. 2011. Variability of Holocene to late Pleistocene Zambezi riverine sedimentation at the upper continental slope off Mozambique. Marine Geology 286: 21-34.

Shchepetkin A, McWilliams JC. 2005. The regional oceanic modeling system (ROMS): a split-explicit, free-surface, topography-following coordinate oceanic model. Ocean Modelling 9: 347-404.

Simpson JH, Hunter JR. 1974. Fronts in the Irish Sea. Nature 250: 404-406.

Sousa LP, Brito A, Abdula S, Caputi N. 2006. Research assessment for the management of the industrial shallow-water multi-species shrimp fishery in Sofala Bank in Mozambique. Fishery Research 77: 207-219.

Tovela EH. 2012. Influence of fronts and water masses in fish stock distribution patterns of Sofala Bank, Mozambique. Master thesis. Eduardo Mondlane University. 


\section{Figures}

Figure 1: Geographic location of the Sofala Bank on the coast of Mozambique. The contours represent the bottom topography $(\mathrm{m})$ and the model domain used for the numerical experiments is shown. The locations of the town of Beira and the tide gauge mooring in the Pungwe River mouth are indicated on the map

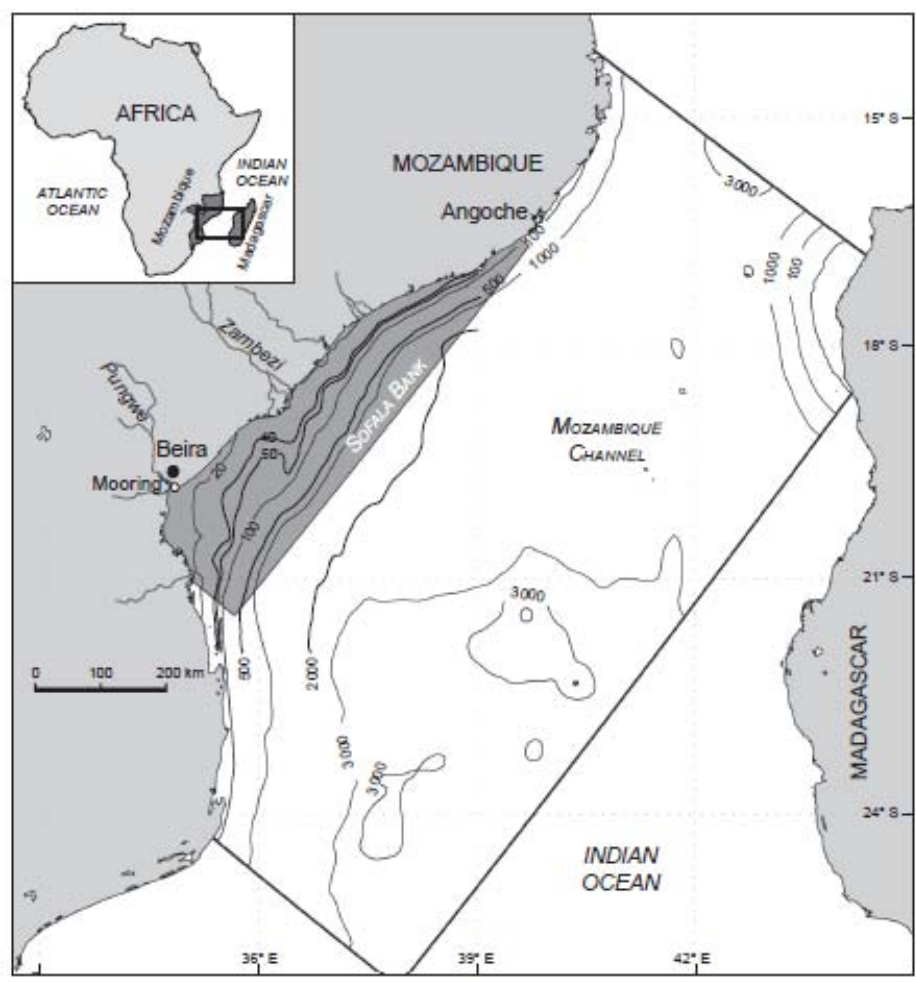


Figure 2: Amplitude (cm) (solid lines) and phase (dashed lines) of the $M_{2}$ tidal constituent from TPXO 7.0 (Egbert and Erofeeva 2002) for the western Indian Ocean. Inset provides an enlarged view of the Sofala Bank region

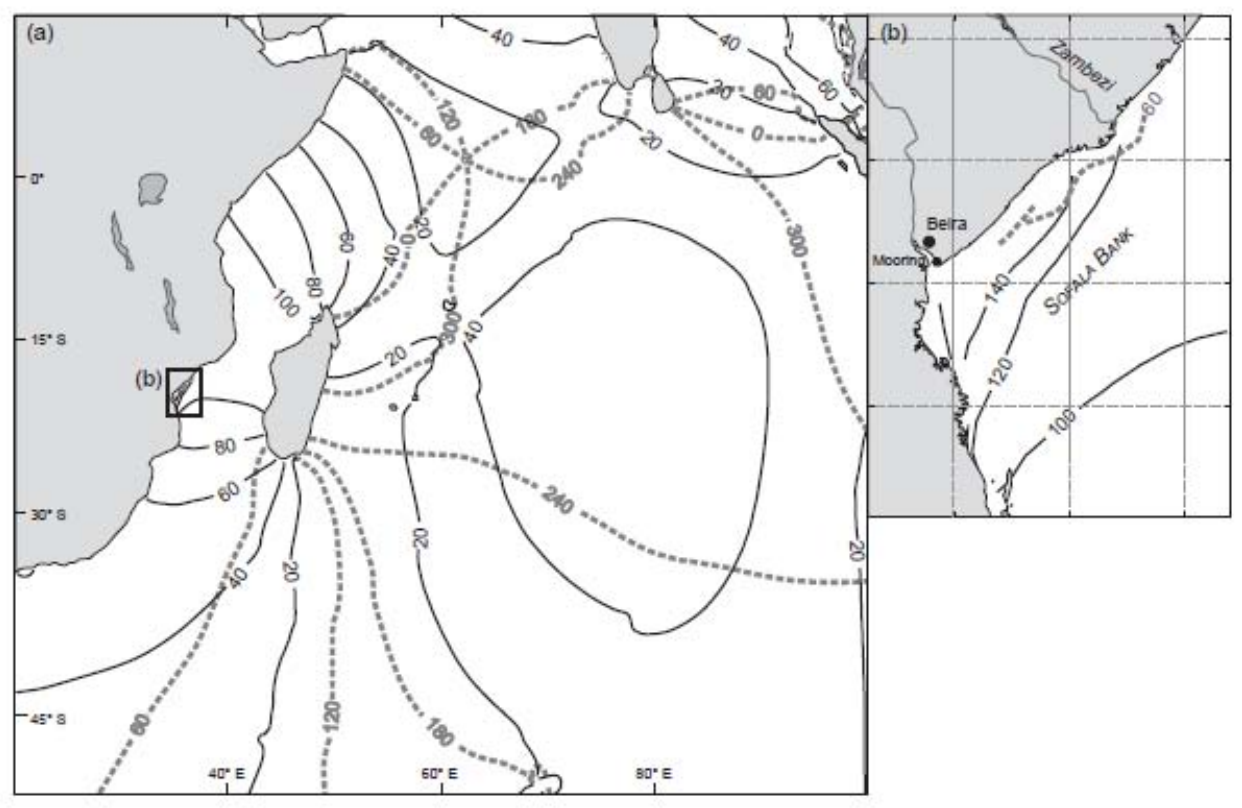

Figure 3: Time-series of sea surface height from 16:00, 9 January 1998, to 00:00, 25 January 1998, at the tide gauge located in Beira: (a) solid line - observations from tide gauge, dashed-dotted line outputs from TPXO 7.0 (at $20^{\circ} \mathrm{S}, 35.05^{\circ} \mathrm{E}$ ); (b) solid line - observations from tide gauge, dashed line - outputs from ROMS simulation

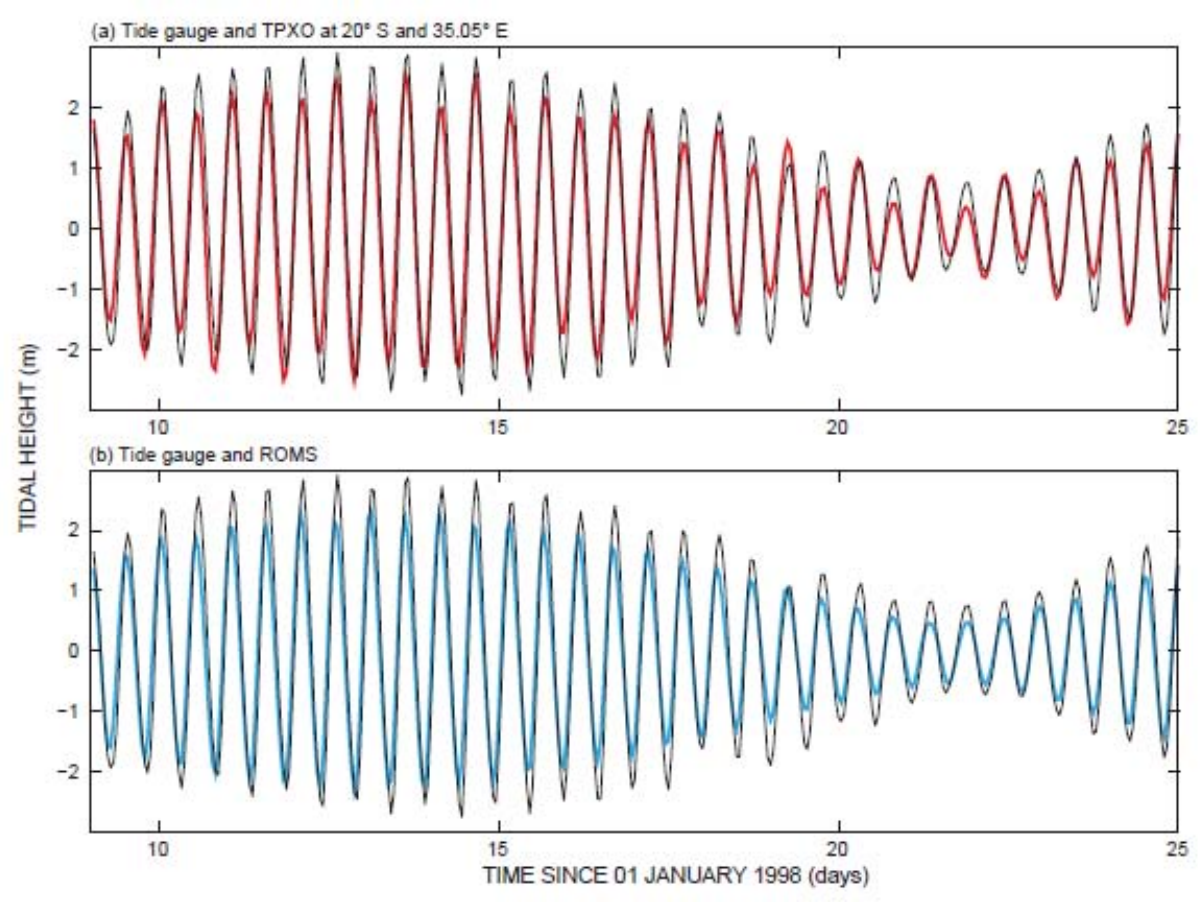


Figure 4: Tidal cycle of sea surface elevation $(\mathrm{m})$ during a typical spring tide, represented here on 28 March of Model Year 1. Each panel is lagged by 2 hours, starting from high tide or low tide: (a) high tide; (b), (c) ebbing tide; (d) low tide; (e, f) flooding tide

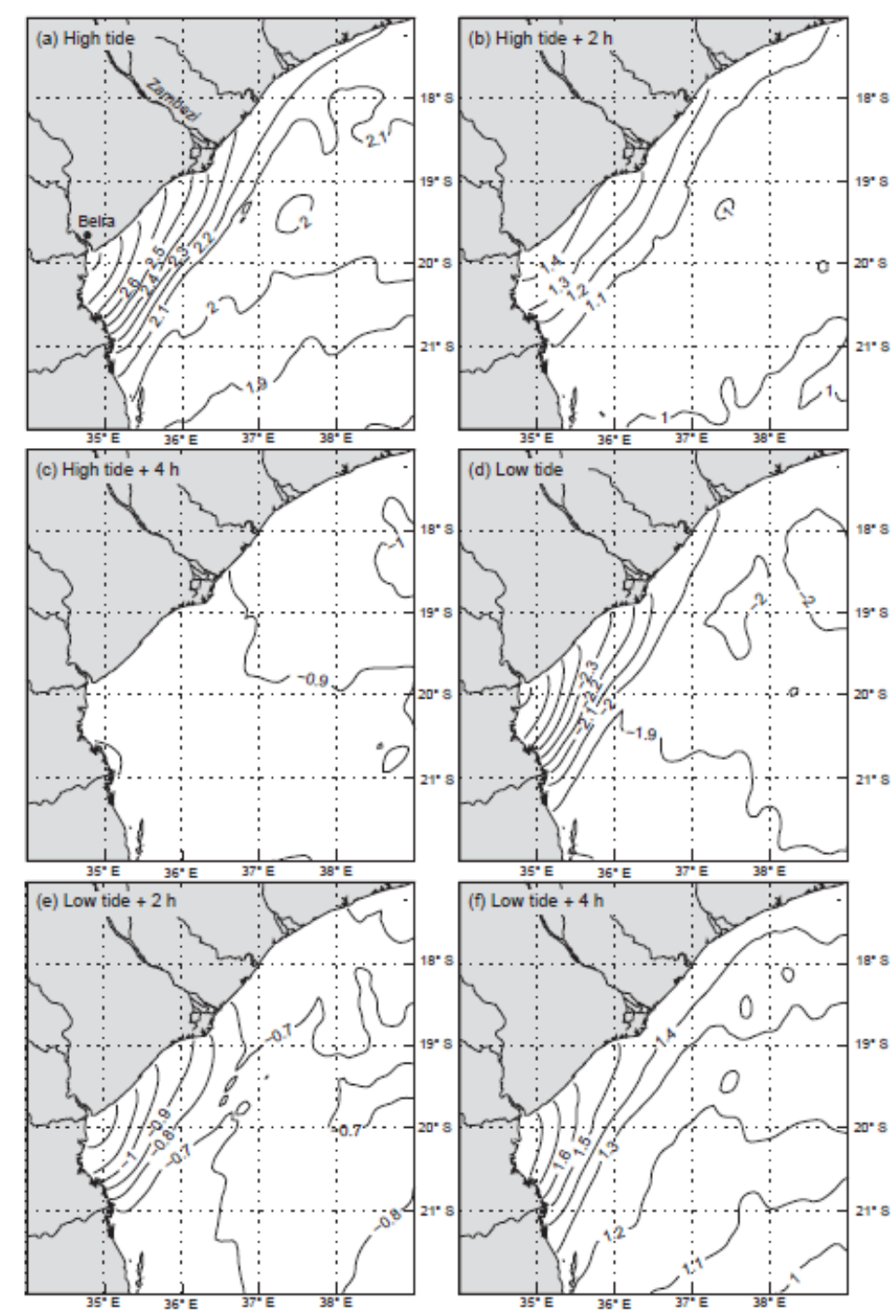


Figure 5: Speed and direction of the vertically averaged currents for the same time period and intervals as in Figure 4
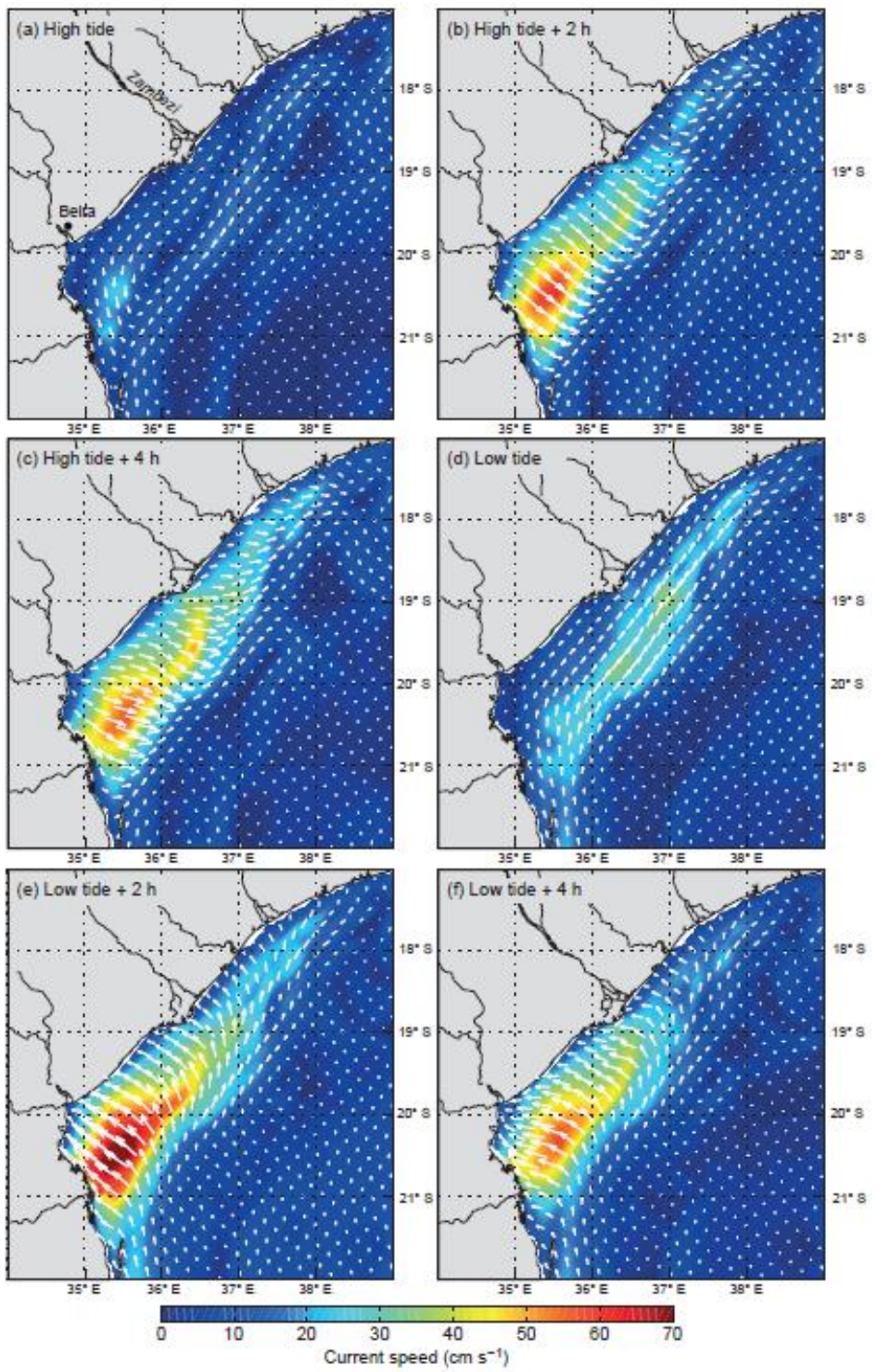
Figure 6: (a, b) Tidal amplitude (cm), (c, d) phase $\left({ }^{\circ}\right)$ and $(e, f)$ ellipses for the two major tidal components $\left(M_{2}\right.$ and $\left.S_{2}\right)$ derived using $T_{-}$tides from the model vertically averaged velocities. Solid red lines account for the model solution (ROMS) and dashed blue lines for TPXO 7.0. Ellipses are derived from the model solution. The red ellipses indicate a counterclockwise rotation and the blue ellipses a clockwise rotation

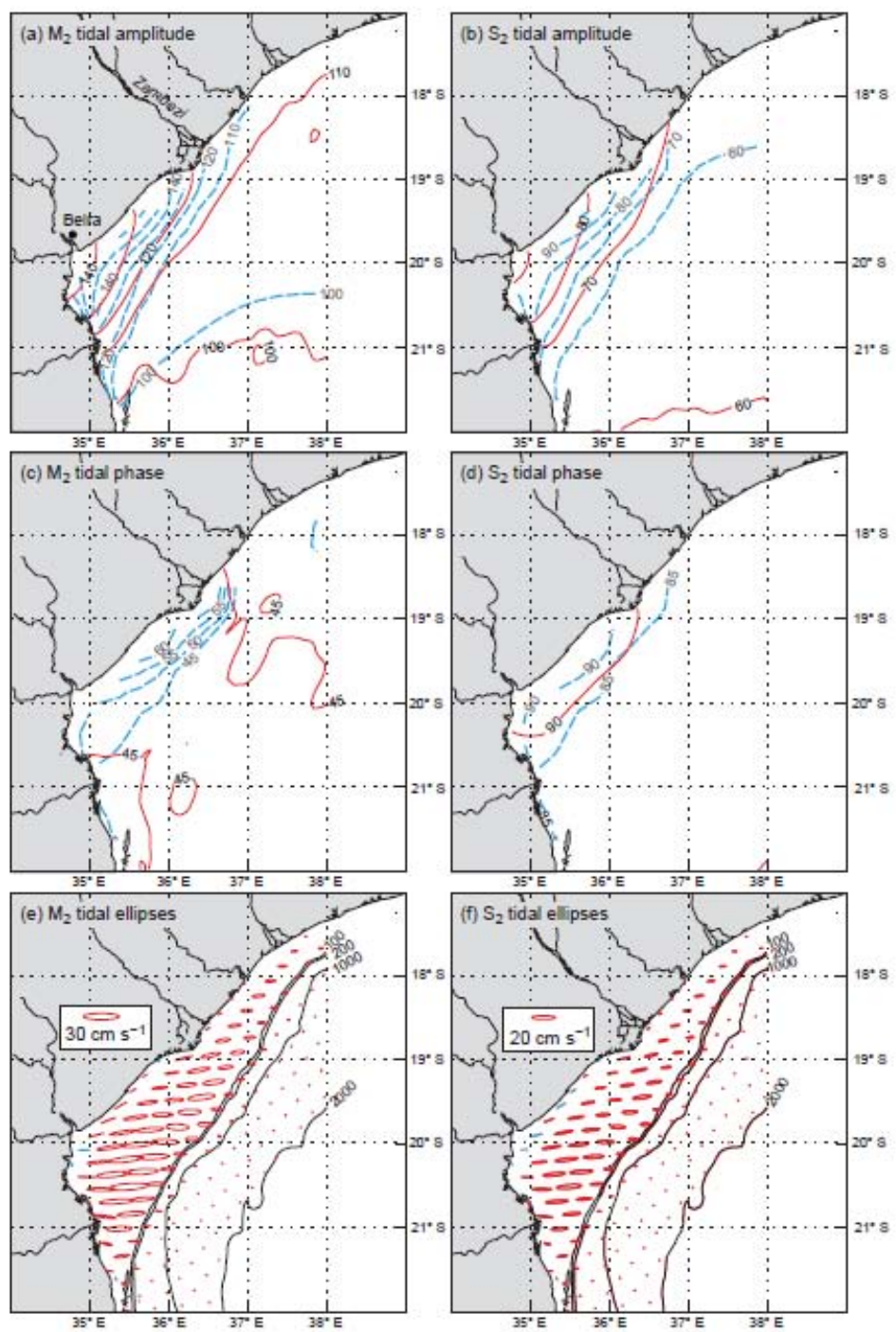


Figure 7: (a) Mean and (b) $95^{\text {th }}$ percentile of kinematic bottom stress $\left(\mathrm{N}^{2} \mathrm{~m}^{-2}\right)$ derived from Day 20 to Day 100 of the ROMS model solution

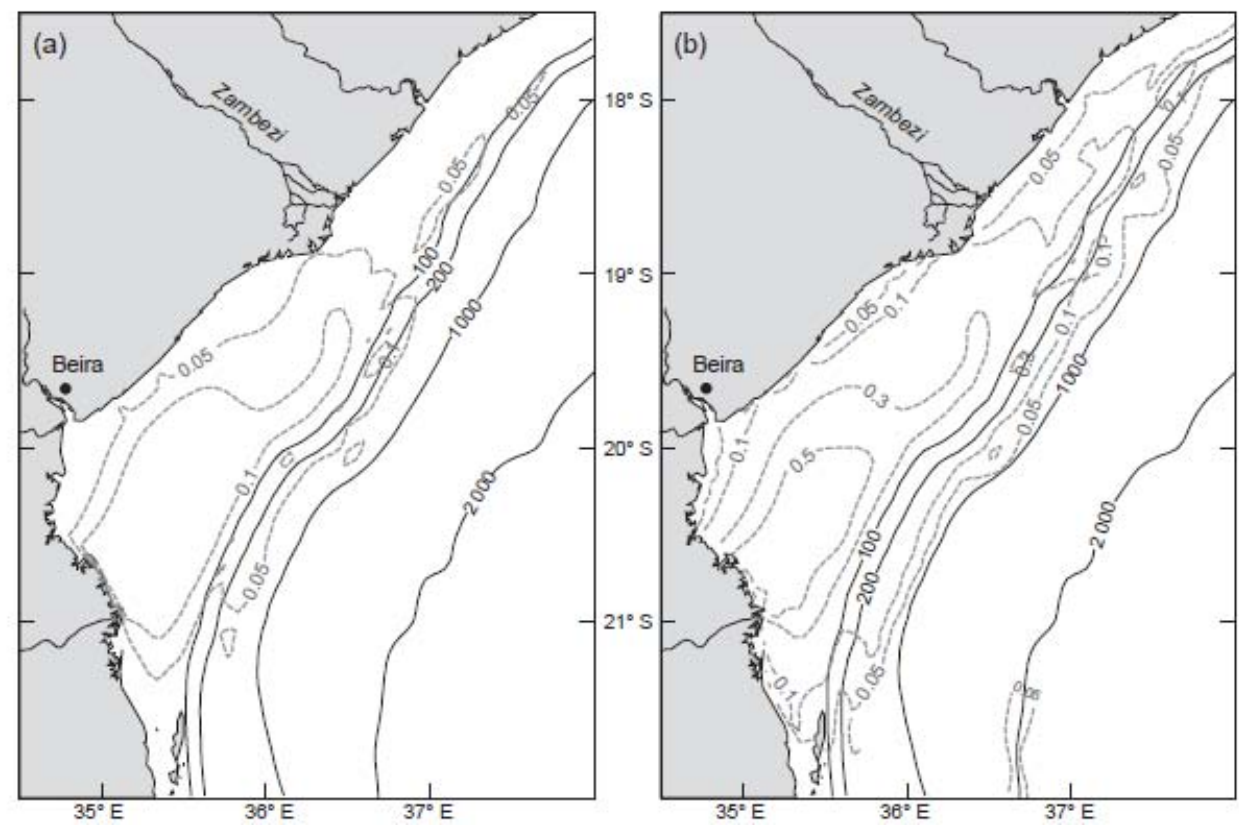

Figure 8: Vertical section of annual mean temperature across the Sofala Bank for (a) the ROMS model solution and (b) CARS climatology. The position of the section is shown in Figure 9a

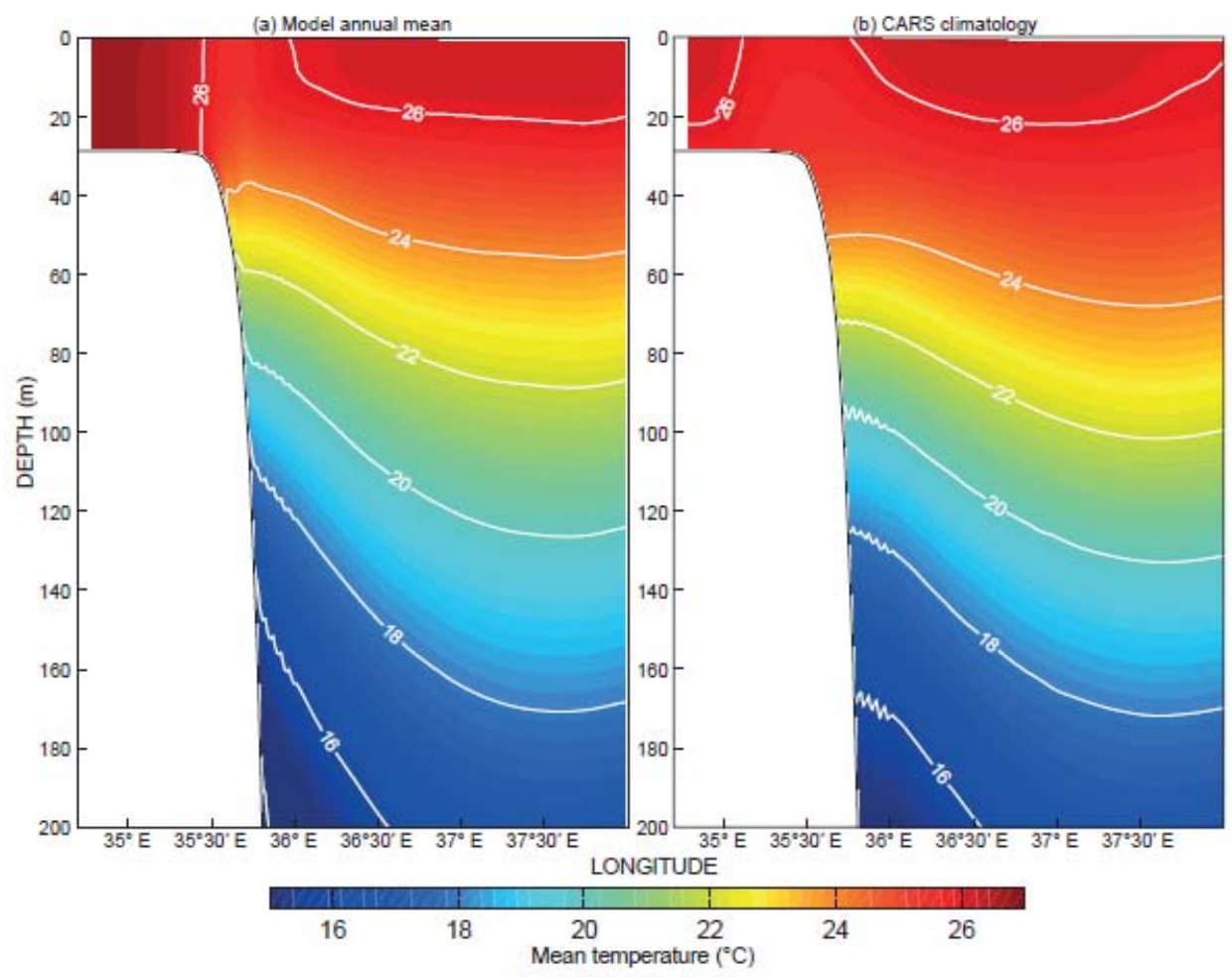


Figure 9: (a) Annual mean sea surface temperature (SST), with the bold line showing the position of the vertical section; (b) vertical section of annual mean temperature, with the three different regions (I-III) indicated
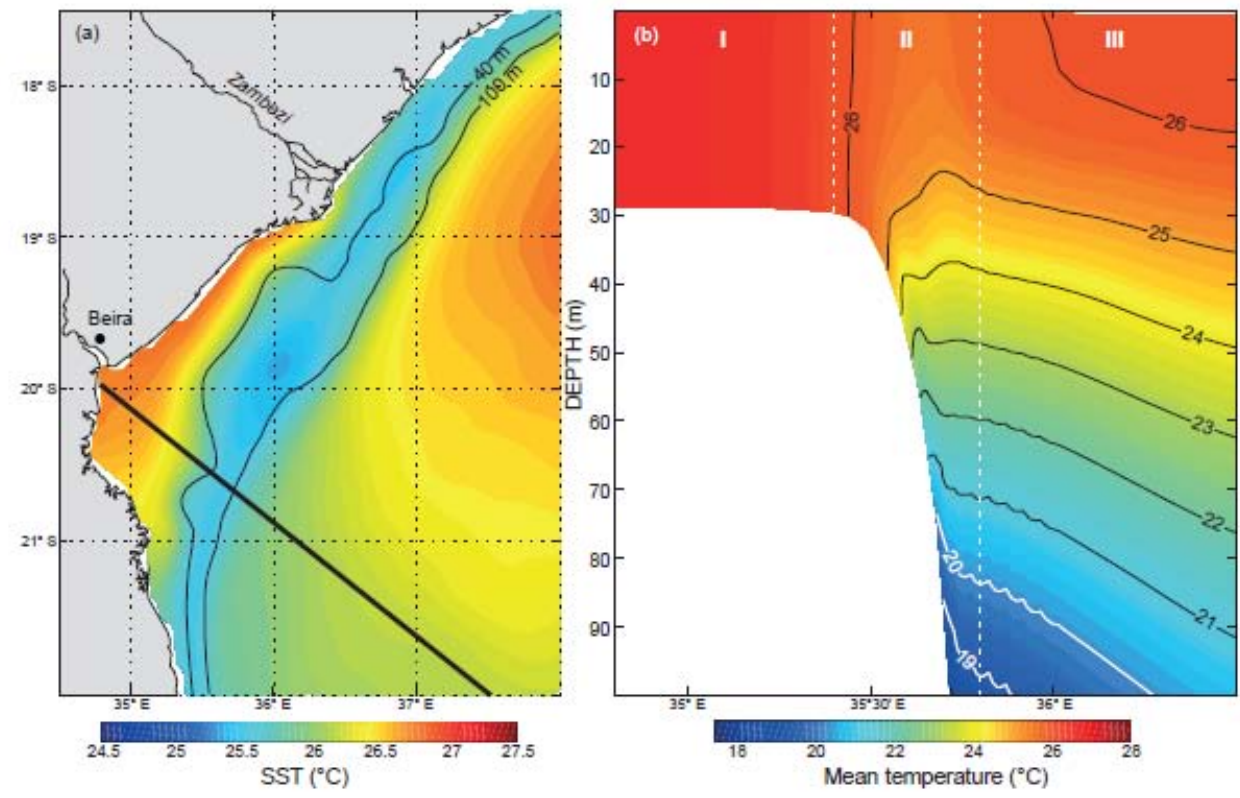

Figure 10: Annual mean sea surface temperature (SST) from Pathfinder 5.0 climatology

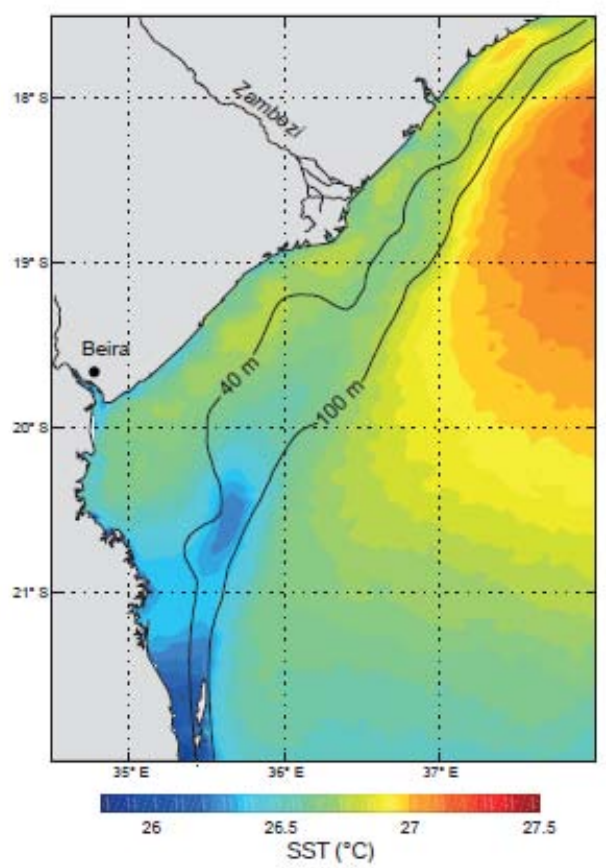


Figure 11: (a) Annual mean sea surface temperature (SST) for the simulation without tides, with the bold line showing the position of the vertical section; (b) vertical section of annual mean temperature
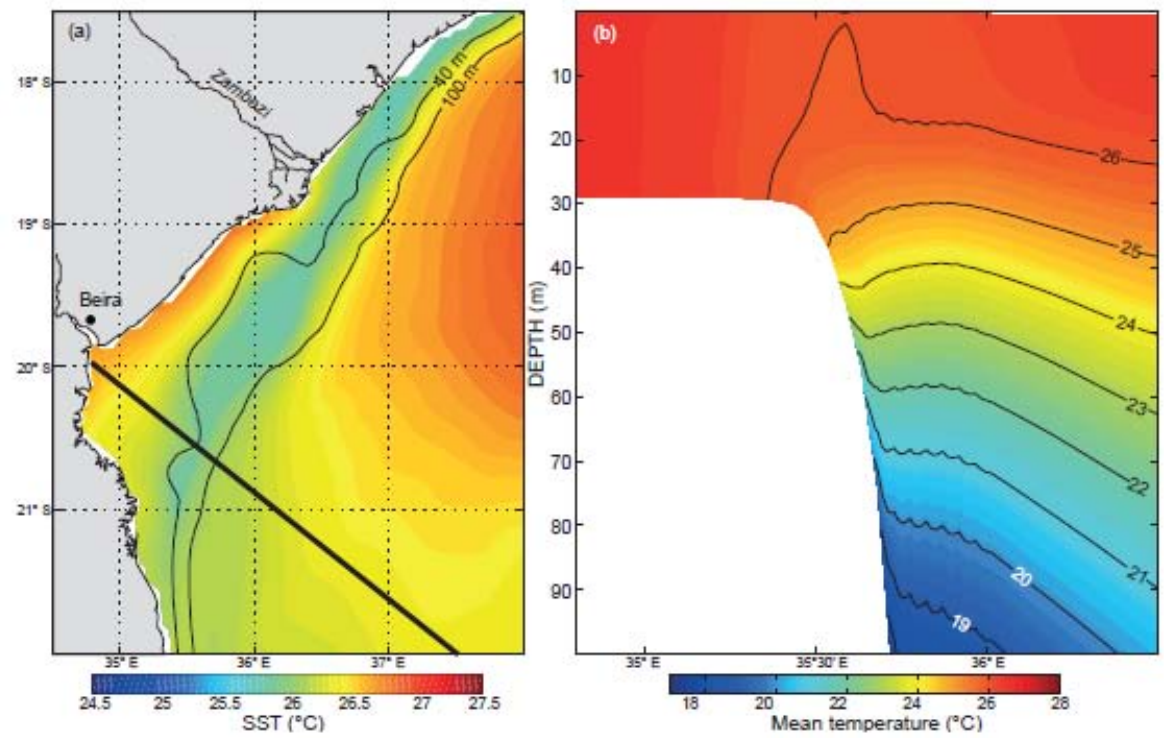

Figure 12: Contours representing the Simpson Hunter (1974) parameter, $\log _{10}\left(h / U^{3}\right)$, overlaid on modelled annual mean SST difference $\left({ }^{\circ} \mathrm{C}\right)$ between the model simulations with and without tides. The dashed contours represent bottom topography $(\mathrm{m})$ and the red contour encompasses a region where $\log _{10}\left(h / \cup^{3}\right)<3.2$ and the bottom topography $>30 \mathrm{~m}$, i.e. a region where tidal mixing is sufficient to mix the full water column, but which is deep enough to stay cool

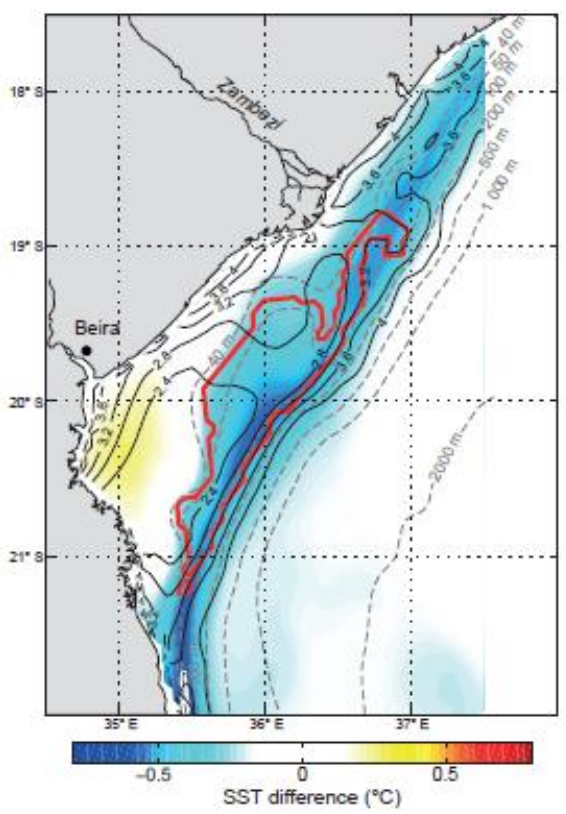


Figure 13: Vertical sections of model temperature at 2-hour intervals from high spring tide on 9 March of Model Year 10. The position of the section is given in Figure 9a

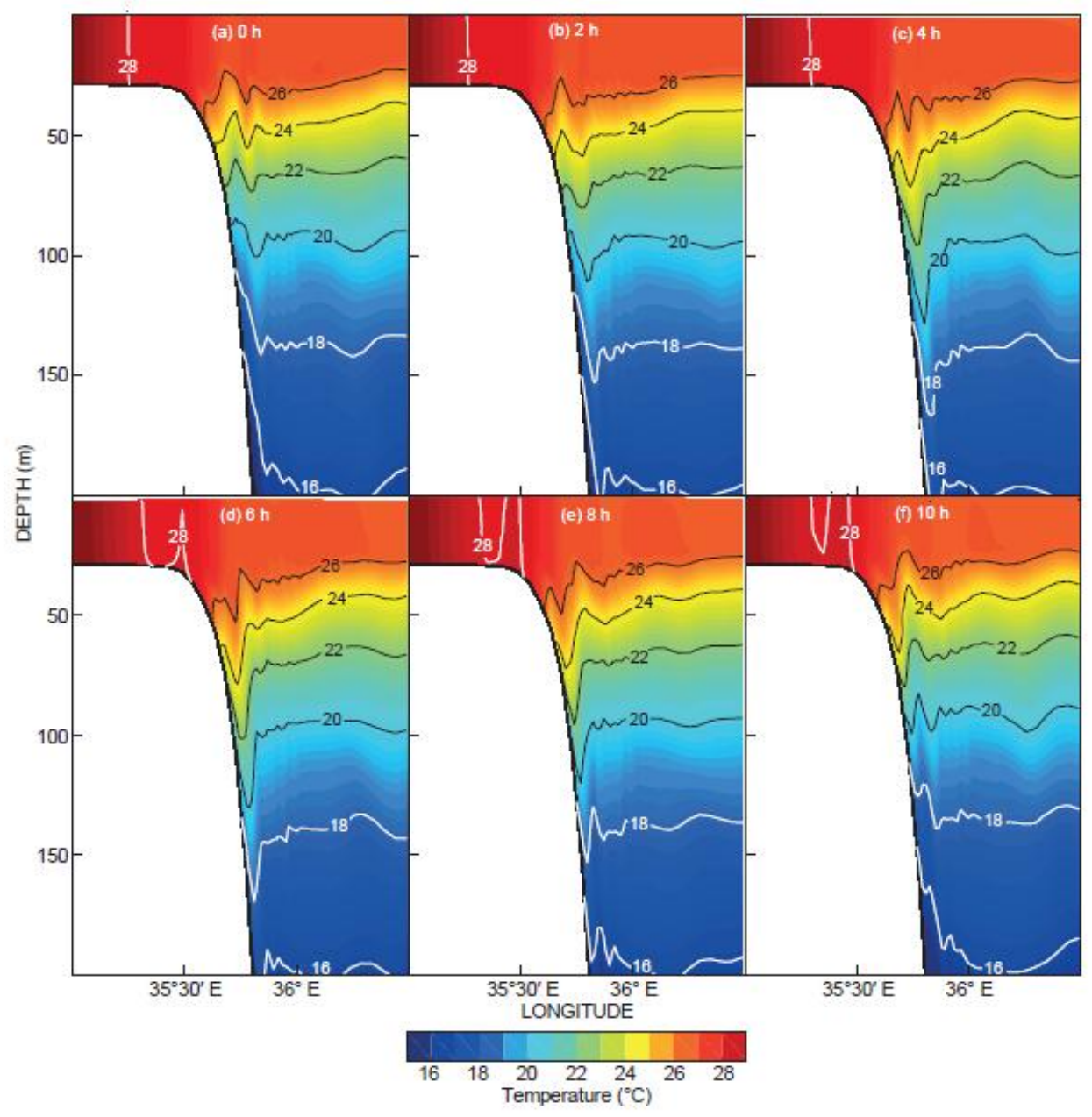

